\title{
Diethylketone and Cd pilot-scale biosorption by a biofilm supported on vermiculite
}

\author{
F. Costa \& T. Tavares \\ Centre of Biological Engineering, University of Minho, Braga, Portugal
}

\begin{abstract}
The pilot-scale assays conducted with a joint bacteria-clay systemStreptococcus equisimilis ( $S$. equisimilis) biofilm supported on vermiculite-were conducted in a close loop reactor aiming the decontamination of large volumes of binary aqueous solutions containing diethylketone and $\mathrm{Cd}^{2+}$. The joint system employed proved to be able to simultaneously biodegrade diethylketone and biosorb $\mathrm{Cd}^{2+}$ : the removal (biodegradation and/or biosorption) percentage and the uptake increase through time, even with the replacement of the initial solution by new solutions.
\end{abstract}

\section{INTRODUCTION}

Contamination of aquatic systems has become a serious problem to society due to the ever-increasing use of modern agricultural practices, the rapid and growing industrialization, the illegal discharges of wastewater and the ruthless exploitation of natural resources (Bhuvaneshwari and Sivasubramanian 2014). These practices introduce dangerous and persistent compounds like organic solvents and metallic compounds in the environment, which tend to accumulate in and deteriorate the different environmental matrices (Murthy et al. 2012). On a small scale, both organic and inorganic pollutants can safely be separated from any water body and thus not affecting the aquatic communities. However, on a larger scale, the aquatic systems are unable, in due time, to successfully decontaminate the contaminated water bodies (Bhuvaneshwari and Sivasubramanian 2014). In this context, the understanding of the contaminants migration between the different phases and of the parameters affecting the decontamination processes (biodegradation, biosorption and sorption for example) and the development of techniques able to efficiently and effectively decontaminate wastewater are of utmost importance. In the past few years, several studies have proved that biological processes such as biodegradation or biosorption present various advantages over the traditional techniques and methods. These biological processes present an eco-friendly character since they do not produce nitrogen oxides and solid wastes, present high efficiency and reduced maintenance and operational costs (Costa et al. 2012).

Volatile organic compounds and metals are expected to be among the high variety of contaminants present in industrial and/or domestic effluents (Azeez et al. 2013). Several studies concerning the decontamination of such effluents and its optimization have been conducted and became of major importance and relevance not only for environment rehabilitation, but also aiming its economics sustainability.

In this work, a joint system that combines the properties of bacteria and clays was used to improve the decontaminations of binary aqueous solutions, composed by diethylketone and cadmium $\left(\mathrm{Cd}^{2+}\right)$. The scarcity of studies related to the decontamination of multi-component solutions highlights the importance of the work herein presented. 


\section{MATERIALS AND METHODS}

\subsection{Support, microorganisms and chemicals}

Vermiculite was purchased from Sigma-Aldrich and it was used as a support for the bacterial biofilm establishment and development

The bacterium used was Streptococcus equisimilis and it was acquired from the Spanish Type Culture Collection, from the University of Valencia (reference CECT 926).

Diethylketone was acquired from Acros Organics (98\% pure) and diluted in sterilized distilled water. Individual stock solutions of $1 \mathrm{~g} / \mathrm{L}$ of cadmium $\left(\mathrm{CdSO}_{4} \cdot 8 / 3 \mathrm{H}_{2} \mathrm{O}\right.$, Riedelde-Haën) were prepared by dissolving a correctly weighed amount of metal in sterilized distilled and deionised water. Previous assays performed at lab-scale in batch mode to assess the effect of the concentration of diethylketone, and $\mathrm{Cd}^{2+}$, on singular and binary solutions, on the growth of $S$. equisimilis and on the sorption capacity of $S$. equisimilis, vermiculite, and a S. equisimilis biofilm supported on vermiculite are reported by our team in Costa et al. (2014) and Quintelas et al. (2011, 2012).

\subsection{Bioremoval of diethylketone and $\mathrm{Cd}^{2+}$ by a $\mathrm{S}$. equisimilis biofilm supported in vermiculite - pilot scale experiments}

A compact polycarbonate acrylic column of $22.7 \mathrm{~L}$ with an internal diameter of $17 \mathrm{~cm}$ and a total height of $100 \mathrm{~cm}$ was used as a bioreactor in the pilot scale experiments. A maximum packing fraction of $1 / 3$ of the bioreactor was filled with vermiculite $(700 \mathrm{~g})$. A 2 L Erlenmeyer flask containing $1 \mathrm{~L}$ of Brain Heart Infusion culture medium, previously sterilized at $121^{\circ} \mathrm{C}$ for 20 minutes was inoculated with $S$. equisimilis and incubated for 24 hours at $37^{\circ} \mathrm{C}$ and $150 \mathrm{rpm}$ in an orbital shaker. The Erlenmeyer flask was capped with a cotton stopper in order to permit passive aeration. The inoculum culture was posteriorly transferred to the bioreactor setup and was pumped upwards at a flow rate of $250 \mathrm{~mL} / \mathrm{minute}$, during five days with total recirculation, in order to allow the biomass to attach to the vermiculite and form a biofilm. After the biofilm development, the bed was washed out and a $40 \mathrm{~L}$ solution containing $7.5 \mathrm{~g} / \mathrm{L}$ of diethylketone and $100 \mathrm{mg} / \mathrm{L}$ of $\mathrm{Cd}^{2+}\left(\mathrm{S}_{1}\right)$ was continuously pumped upwards in close loop through the bioreactor with a constant flow rate of $25 \mathrm{~mL} /$ minute. The first solution $\left(S_{1}\right)$ was posteriorly replaced by new solutions $\left(S_{2}\right.$ and $\left.S_{3}\right)$ with identical composition.

At pre-established time intervals, samples of the effluent $(8 \mathrm{~mL})$ were taken (Collection point, Figure 1), centrifuged at $1300 \mathrm{rpm}$ for 10 minutes and the aqueous phase was analysed by Inductively Coupled Plasma Optical Emission Spectrometry (ICP-OES) and by Gas Chromatography Mass Spectrometry (GC-MS) and in order to determine respectively the concentration of $\mathrm{Cd}^{2+}$ and

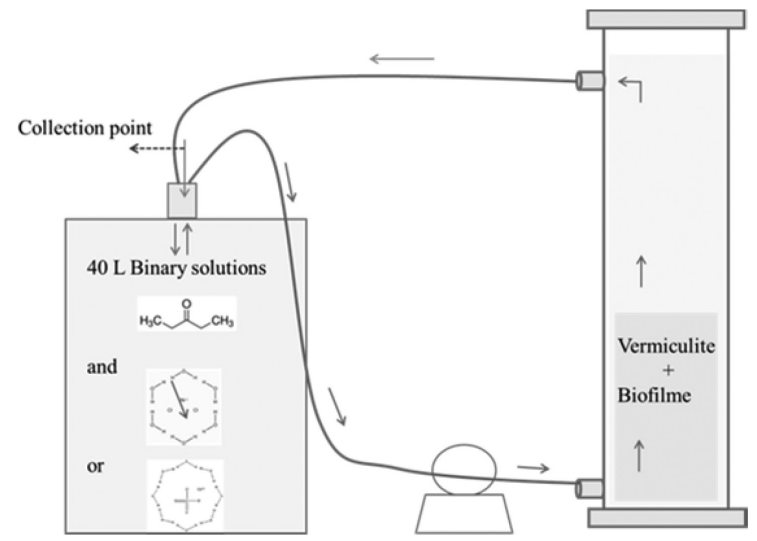

Figure 1. Schematic set-up for the bioreactor column. 
diethylketone through time. At the end, the bioreactor was washed out and samples of the effluent and of the support were inoculated in Petri plates with Brain Heart Infusion culture medium, in order to access about the metabolic activity of the bacteria. The $\mathrm{pH}$ was also monitored.

\subsection{Analytical procedures: ICP, GC, FTIR, XRD AND SEM}

An ICP-OES (Optima 8000, PerkinElmer) was used to determine the concentration of $\mathrm{Cd}^{2+}$. All calibration solutions were prepared from a $\mathrm{Cd}^{2+}$ stock solution with a concentration of $1 \mathrm{~g} / \mathrm{L}$. All the samples were acidified with concentrated nitric acid $\left(\mathrm{HNO}_{3} 69 \%\right)$ and filtered before being analysed. A GC-MS Varian 4000, equipped with a flame ionization detector (FID), mass spectrometry (MS) and a ZB-WAXplus column $(30 \mathrm{~m} \times 0.53 \mathrm{~mm} \times 1.0 \mu \mathrm{m})$ was used to determine the concentration of diethylketone in samples.

The functional surface groups implicated in the bioremoval (biodegradation or biosorption) of diethylketone and $\mathrm{Cd}^{2+}$ were determined using a Fourier Transform Infrared Spectrometer (FTIR BOMEM MB 104). The X-ray powder diffraction (XRD) analyses were performed using a Philips PW1710 diffractometer. Scans were taken at room temperature in a $2 \theta$ range between $5^{\circ}$ and $60^{\circ}$, using $\mathrm{CuK} \alpha$ radiation. Scanning Electron Microscopy (SEM) observations of vermiculite with and without previous contact with diethylketone and $\mathrm{Cd}^{2+}$, with and without the biofilm, were performed on Leica Cambridge S360, in order to observe any morphological change on the sorbents properties.

\subsection{Breakthrough curves modelling}

In the present study, the Adams-Bohart, the Yoon and Nelson models and the Wolborska models were used to predict the breakthrough curves (Costa et al., 2017).

\section{RESULTS AND DISCUSSION}

In Figure 2 is possible to observe that the removal (biodegradation and/or biosorption) of diethylketone and $\mathrm{Cd}^{2+}$ is continuous and tends to increase through time and after the replacement of the first solution $\left(\mathrm{S}_{1}\right)$ by new solutions $\left(\mathrm{S}_{2}\right.$ and $\left.\mathrm{S}_{3}\right)$.

This behaviour may be caused by the microbial growth, that in addition to increasing the substrate consumption it also increases the number of active sites of the biofilm, used for $\mathrm{Cd}^{2+}$ sorption, hampering the saturation of active sites present either on the biomass and vermiculite surface. The maximum removal percentage and uptake values obtained for diethylketone and $\mathrm{Cd}^{2+}$ were respectively, $98.2 \%$ and $421.0 \mathrm{mg} / \mathrm{g}$ and $87.6 \%$ and $5.0 \mathrm{mg} / \mathrm{g}$. In Figure 2 and Table 1 is possible to observe that the removal percentage achieved for diethylketone is higher than the removal percentage obtained for $\mathrm{Cd}^{2+}$, which corresponds to removal of $36.23 \mathrm{~mol} / \mathrm{g}$

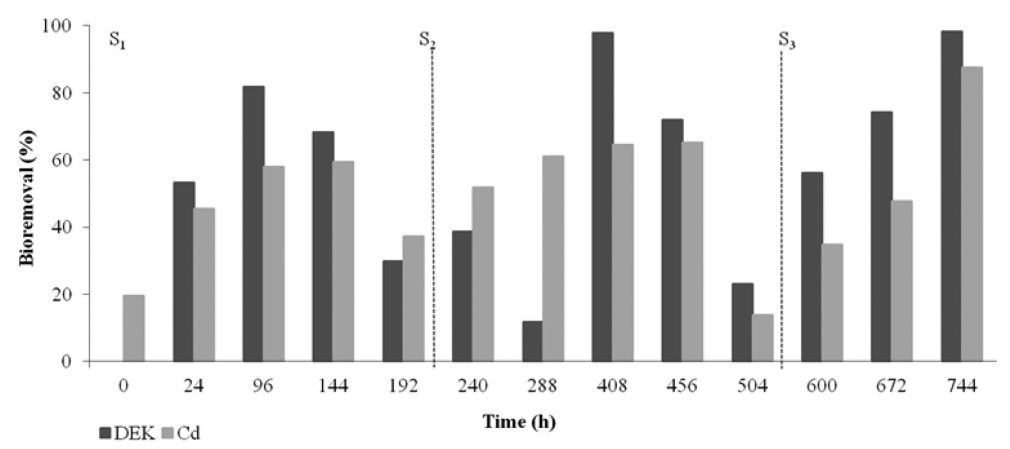

Figure 2. Bioremoval performance (\%) obtained by a S. equisimilis biofilm supported on vermiculite for diethylketone $(7.5 \mathrm{~g} / \mathrm{L})$ and $\mathrm{Cd}^{2+}(100 \mathrm{mg} / \mathrm{L})$, at pilot plant scale. 
Table 1. Biosorption performance of the bioreactor column for diethylketone $(7.5 \mathrm{~g} / \mathrm{L})$ and for $\mathrm{Cd}^{2+}(100 \mathrm{mg} / \mathrm{L})$.

\begin{tabular}{lll}
\hline Maximum bioremoval (\%) & & \\
\hline Time $(\mathrm{h})$ & DEK & $\mathrm{Cd}^{2+}$ \\
\hline $\mathrm{S}_{1}(0 \mathrm{~h}-192 \mathrm{~h})$ & 81.83 & 59.47 \\
$\mathrm{~S}_{2}(192 \mathrm{~h}-504 \mathrm{~h})$ & 97.85 & 65.27 \\
$\mathrm{~S}_{3}(504 \mathrm{~h}-744 \mathrm{~h})$ & 98.24 & 87.64 \\
\hline
\end{tabular}

of diethylketone and $0.56 \mathrm{~mol} / \mathrm{g}$ of $\mathrm{Cd}^{2+}$. The results obtained may be explained since diethylketone can either be entrapped by the functional groups present on the biofilm and on the vermiculite surface or it can also suffer biodegradation by the microbial culture. The $\mathrm{pH}$ was found to freely range between 6 and 7 since the beginning of the experiment till its end, which according to the literature and the results obtained previously, is within the optimal range for $\mathrm{Cd}^{2+}$ sorption by vermiculite and is close to the optimum $\mathrm{pH}$ for the growth of $S$. equisimilis (7.4). Previous experiments conducted with different initial values of $\mathrm{pH}(\mathrm{pH} \mathrm{3,5.5}$ and 8) and vermiculite revealed that the $\mathrm{pH}$ of the system has the capacity to return and maintain to $\mathrm{pH}$ values close to $\mathrm{pH}$ 7.This behaviour represents an additional significative and important advantage since no adjustment of $\mathrm{pH}$ is required.

The viability tests conducted at the end of the pilot scale assays revealed that $S$. equisimilis biofilm presents biological activity, which is an important advantage in the treatment of wastewater using microorganisms, since microbial culture resistance allows a continuous treatment of the contaminated solutions trough biological active and/or inactive mechanisms.

The solid residues generated by the term of the pilot-scale experiments may be sent to incineration, which ashes can be subsequently used or they can be reused in new decontamination systems. The latter hypothesis is achievable considering the results obtained in the cell viability tests. It is important to highlight that the purpose of this study and of this type of treatment, as well as its mode of use, consists in the decontaminations of aqueous solutions, such as real effluents, is continuous and open system, thus minimizing or even avoiding the production of solid waste.

\subsection{Breakthrough curves modelling}

The fitting parameters for the breakthrough curves as well as the predicted and experimental breakthrough curves are presented in Table 2 and in Figure 3.

The results obtained for diethylketone are appropriately described by any of the models employed $\left(\mathrm{R}^{2}<0.75\right)$, whereas for $\mathrm{Cd}^{2+}$ the experimental results are best fitted by the AdamsBohart model $\left(\mathrm{R}^{2}>0.80\right)$.

\subsection{FTIR, XRD and SEM analysis}

The FTIR spectra obtained for the different samples analysed in the range of $500 \mathrm{~cm}^{-1}$ to $4000 \mathrm{~cm}^{-1}$ are shown in Figure 4. Succinctly, the clay used, vermiculite, presented several sorption peaks, reflecting the complex nature of the mineral clays.

Some of these band signals were also acknowledged by other authors (Eboigboduin and Biggs 2008) on clays and were found to correspond to surface functional groups responsible for the sorption of toxic substances (Volesky 2007). Samples of vermiculite exposed to diethylketone and samples of the biofilm exposed to diethylketone and $\mathrm{Cd}^{2+}$ reveal the existence of several modifications on the FTIR spectra: either on the intensity, on the shape of the peaks and on the disappearance and/or formation of new peaks. After exposure to diethylketone, bands at $2400 \mathrm{~cm}^{-1}$ and $1400 \mathrm{~cm}^{-1}$ undergo important changes. The intensity of the bands detected at $3500 \mathrm{~cm}^{-1}, 1650 \mathrm{~cm}^{-1}, 1000 \mathrm{~cm}^{-1}$ and $675 \mathrm{~cm}^{-1}$, was found to decrease considerably. All these modifications may be due to the interaction and participation of the functional 
Table 2. Breakthrough parameters obtained for the pilot-scale experiments.

\begin{tabular}{|c|c|c|c|c|c|c|c|c|}
\hline & \multicolumn{3}{|c|}{ Adams-Bohart } & \multicolumn{3}{|l|}{ Wolborska } & \multicolumn{2}{|c|}{$\begin{array}{l}\text { Yoon and } \\
\text { Nelson }\end{array}$} \\
\hline & $k_{A B}(\mathrm{~L} / \mathrm{mg} \mathrm{h})$ & $N_{0}(\mathrm{mg} / \mathrm{L})$ & $R^{2}$ & $\beta_{a}\left(\mathrm{~h}^{-1}\right)$ & $R^{2}$ & $k_{Y N}\left(\mathrm{~h}^{-1}\right)$ & $\tau(\mathrm{h})$ & $R^{2}$ \\
\hline $\mathrm{Cd}^{2+}$ & $9.953 e-5$ & 1.906 & 0.81 & $-1.446 e-3$ & 0.78 & $-3.189 \mathrm{e}-3$ & 160 & 0.74 \\
\hline
\end{tabular}

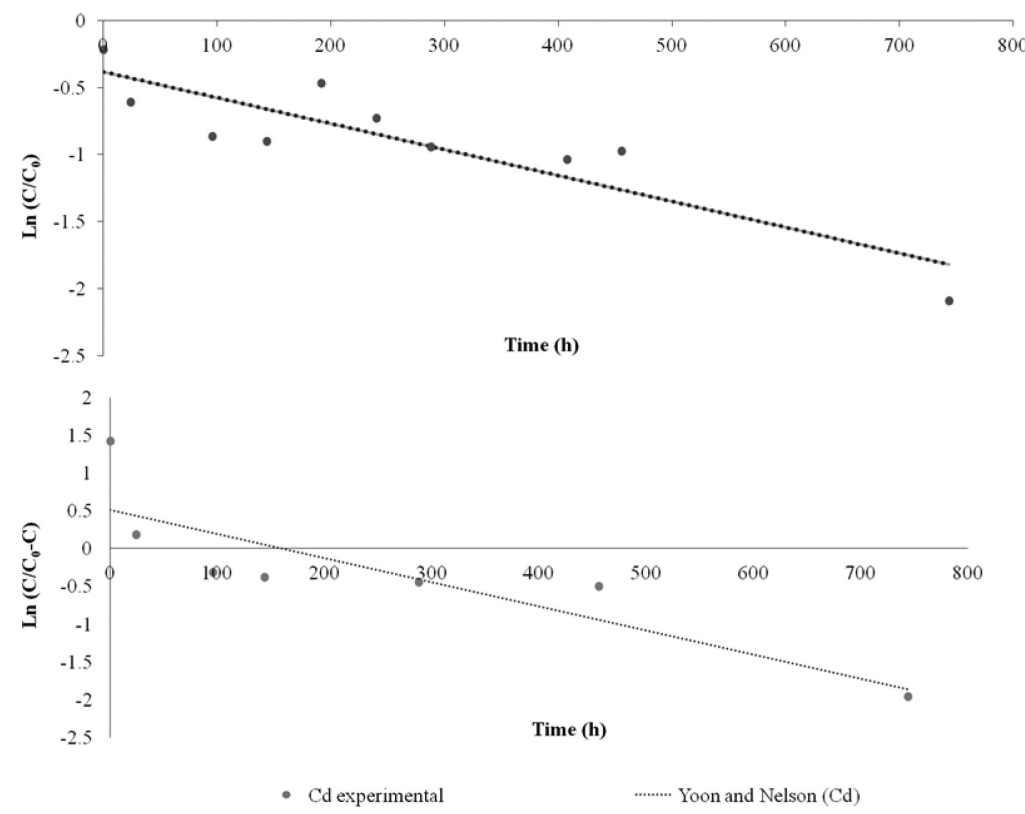

Figure 3. Predicted and experimental breakthrough curves for $\mathrm{Cd}^{2+}$ at pilot-scale.

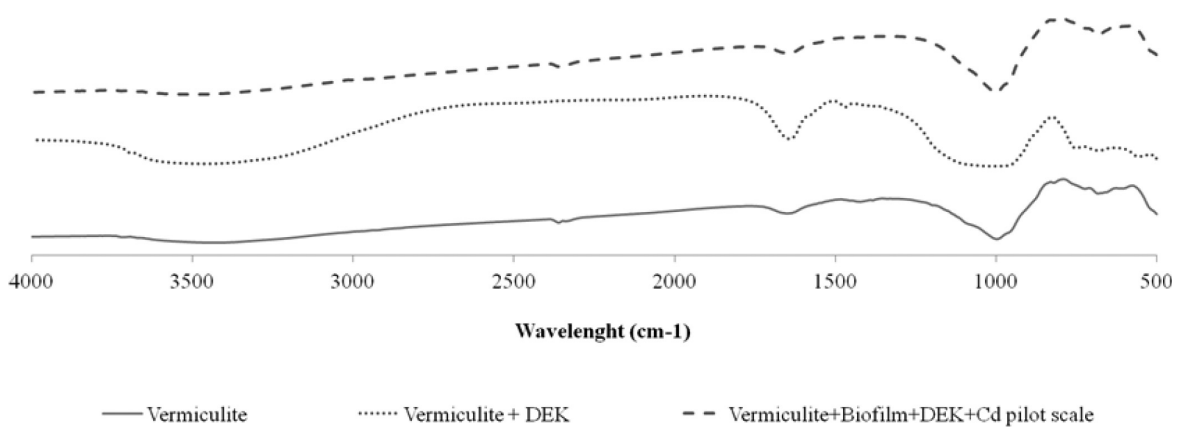

Figure 4. FTIR spectra of different samples: vermiculite unloaded, vermiculite exposed to diethylketone, $S$. equisimilis biofilm supported on vermiculite, loaded with diethylketone and $\mathrm{Cd}^{2+}$.

groups present both in the vermiculite and in the biofilm surface with the functional groups $(\mathrm{C}=\mathrm{O})$ of diethylketone. Bands at $3500 \mathrm{~cm}^{-1}$ and at $2300 \mathrm{~cm}^{-1}$ were found to disappear on the $S$. equisimilis biofilm supported into vermiculite and exposed to diethylketone and to $\mathrm{Cd}^{2+}$ samples. According to Volesky (2007) the major functional groups accountable for biosorption processes are phosphodiester, carboxyl, amide, hydroxyl, phosphonate and carbonyl groups. 


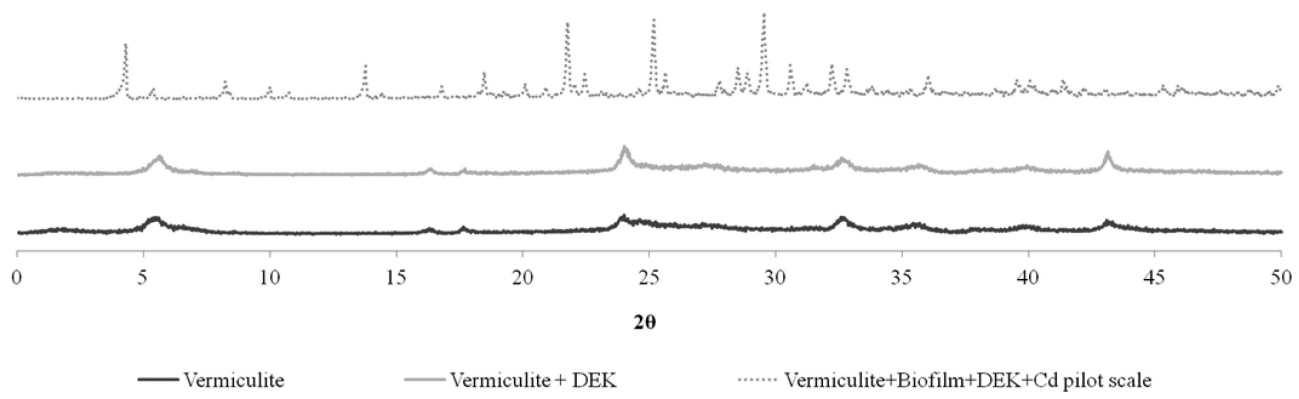

Figure 5. XRD patterns of original and recovered vermiculite.
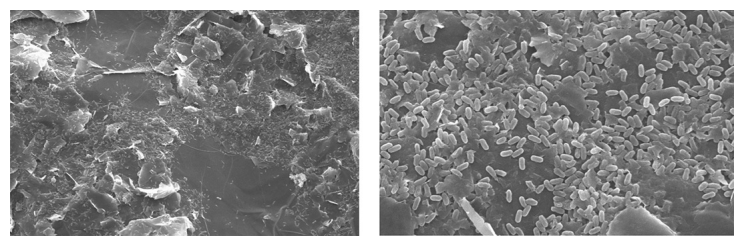

Figure 6. SEM images of $S$. equisimilis supported on vermiculite and exposed to diethylketone and $\mathrm{Cd}^{2}$ for 456 hours (amplification of 3000x).

Some of these functional are present on the Streptococcus sp surface and are responsible for the biodegradation and biosorption of toxic compounds like diethylketone (Costa et al. 2014).

The XRD patterns of different samples were recorded at $2 \theta$ range between $5^{\circ} \mathrm{C}$ and $60^{\circ} \mathrm{C}$ and some representative patterns are presented in Figure 5.

The unloaded and loaded samples of vermiculite with diethylketone showed the characteristic pattern of clays, with no evident change in the position of the diffraction peaks after exposure to the ketone used. This resemblance between the two diffractograms suggests a similar crystallinity of vermiculite before and after exposure to the contaminants, revealing that no significant structural modification in the clay occurred. Nonetheless, the samples containing the biofilm supported into vermiculite, exposed simultaneously to diethylketone and $\mathrm{Cd}^{2+}$ revealed numerous changes, not only in their intensity but also on the position of the diffraction peaks. These changes are an evidence of the extensive actions on the clay structure.

SEM analyses confirm (a) that vermiculite exposure (without biofilm) to diethylketone and $\mathrm{Cd}^{2+}$ makes vermiculite surface more glazed and polished, with broken and worn leaves, (b) the presence of a well-developed bacterial biofilm supported on vermiculite (Figure 6) and (c) the presence of numerous white incrustations on the surface of the sorbent, which correspond to the binding of the metal ions to the surface of biomass and are a evidence of the biosorption of the metal by the biofilm (Sharma et al., 2008).

\section{CONCLUSIONS}

The joint system herein presented has proven to be capable to decontaminate efficiently and continuously, aqueous solutions containing high concentrations of diethylketone and $\mathrm{Cd}^{2+}$ without adjusting the $\mathrm{pH}$. Both the bioremoval percentage and the uptake values increase through time, even after replacing the initial solution by new solutions. The results achieved for $\mathrm{Cd}^{2+}$ were found to be best described by the Adams-Bohart model. The FTIR and SEM analyses proved the existence of a well-established biofilm, with functional groups recognized as responsible for the sorption of toxic compounds. The XRD analyses demonstrated that the exposure of the support, with or without the biofilm, to both contaminants alters significantly 
the structure of vermiculite. It is therefore possible to infer that the developed joint system presents very major advantages concerning the simultaneous treatment of binary solutions.

\section{ACKNOWLEDGEMENTS}

This study was supported by the Portuguese Foundation for Science and Technology (FCT) under the scope of the research project PTDC/AAG-TEC/5269/2014, the strategic funding of UID/BIO/04469/2013 unit and COMPETE 2020 (POCI-01-0145-FEDER-006684) and BioTecNorte operation (NORTE-01-0145-FEDER-000004) funded by the European Regional Development Fund under the scope of Norte2020-Programa Operacional Regional do Norte. Filomena Costa thanks FCT for a PhD Grant (SFRH/BD/77666/2011).

\section{REFERENCES}

Azeez, L. Adeoye, M.D. Lawa, A.T. Idris, Z.A. Majolagbe, T.A. Agbaogun, B.K.O. Olaogur, M.A. 2013. Assessment of volatile organic compounds and heavy metals concentrations in some Nigerianmade cosmetics. Analytical Chemistry: An Indian Journal 12: 443-483.

Bhuvaneshwari, S. Sivasubramanian, V. 2014. Equilibrium, Kinetics, and Breakthrough Studies for Adsorption of $\mathrm{Cr}(\mathrm{VI})$ on Chitosan. Chemical Engineering Communications 201: 834-854.

Costa, F. Quintelas, C. Tavares, T. 2012. Kinetics of biodegradation of diethylketone by Arthrobacter viscosus. Biodegradation 23: 81-92.

Costa, F. Quintelas, C. Tavares, T. 2014. An approach to the metabolic degradation of diethylketone (DEK) by Streptococcus equisimilis: Effect of DEK on the growth, biodegradation kinetics and efficiency. Ecological Engineering 70: 183-188.

Costa, F. Tavares, T. 2017. Sorption studies of diethylketone in the presence of $\mathrm{Al}^{3+}, \mathrm{Cd}^{2+}, \mathrm{Ni}^{2+}$ and $\mathrm{Mn}^{2+}$, from lab-scale to pilot scale. Environmental Technology. DOI: 10.1080/09593330.2016.1278462.

Eboigboduin, K.E. Biggs, C.A. 2008. Characterization of the extracellular polymeric substances produced by Escheria coli using infrared spectroscopic, proteomic and aggregation studies. Biomacromolecules 9: 686-695.

Murthy, S. Bali, G. Sarangi, S.K. 2012. Biosorption of Lead by Bacillus cereus Isolated from Industrial Effluents. British Biotechnology Journal 2: 73-84.

Quintelas, C. Costa, F. Tavares, T. 2012. Bioremoval of diethylketone by the synergistic combination of microorganisms and clays: Uptake, removal and kinetic studies. Environmental Science Pollution Research 20: 1374-1383.

Quintelas, C. Figueiredo, H. Tavares 2011. The effect of clay treatment on remediation of diethylketone contaminated wastewater: Uptake, equilibrium and kinetic studies. Journal of Hazardous Materials 186. 1241-1248.

Sharma, M., Kaushik, A., Somvir, B.K., Kamra, A. 2008. Sequestration of chromium by exopolysaccharides. Journal of Hazardous Materials 157: 315-318.

Volesky, B. 2007. Biosorption and me. Water Research 41: 4017-4029. 